\title{
Effectiveness of Antipyretic with Tepid Sponging Versus Antipyretic Alone in Febrile Children: A Randomized Controlled Trial
}

\section{Chetak KB ${ }^{1}$, Gowri PS², MD Ravi}

\begin{abstract}
Introduction: Fever is the most common presenting complain for which children are brought to the paediatrician.Physical methods are widely used in treating febrile children, tepid sponging being commonly practiced in hospitals along with antipyretics. The objectives of this study were to compare the effectiveness of tepid sponging and antipyretic drug versus antipyretic drug alone in febrile children. Material and Methods: This was a Randomized controlled trial done in JSS Medical College and Hospital. All children under the age of 6 months to 12 years, admitted with axillary temperature of $>99^{\circ} \mathrm{F}$ were included in the study. A total of 500 children were included over two years study period. Children with recorded axillary temperature of $>99^{\circ} \mathrm{F}$ were randomized into control and study group by computer generated randomisation. Children in the control group received only paracetamol $(15 \mathrm{mg} / \mathrm{kg})$ at 5 minutes and combined group received paracetamol and tepid sponging at five minutes. Axillary temperature was monitored every 15 minutes for a period of 2 hours in both the groups. Results:There is no significant difference in reduction of temperature between the two groups by the end of two hours. Children in combined group had a higher level of discomfort than those in only antipyretic group. Conclusion:Tepid sponging does not add to the efficacy of paracetamol in antipyresis and that addition of tepid sponging to antipyretic, results in additional discomfort for the child. This study, therefore, endorses the view that antipyretic alone without tepid sponging should be the modality of therapy in children with fever.
\end{abstract}

Key words: Antipyretic drug, Fever,Tepid sponging.

\section{Introduction}

Eever can be defined as an elevation of body temperature above - the normal daily variation ${ }^{1}$.It is one of the most common reasons that parents seek medical attention for their children. Parental concerns arise because of the belief that fever is a disease rather than a symptom or the sign of illness ${ }^{2}$.Fever phobia, an exaggerated fear of fever in their children, is common among parents of all socioeconomic classes ${ }^{1,3}$. Children with fever often experience discomfort,
${ }^{1}$ Dr. Chetak K B, MBBS. MD. Assistant Professor, ${ }^{2} \mathrm{Dr}$. P Shyamala Gowri, MBBS. MD Post Graduate, ${ }^{3} \mathrm{Dr}$. MD Ravi, MBBS, MD, Director and Professor of Paediatrics. All from the Department of Paediatrics, Jagadguru Sri Shivarathreeshwara Medical College and Hospital, MG Road, Mysore.

\section{Address for correspondence \\ Dr. Chetak KB, Assistant Professor, Department of Paediatrics, JSS Medical College and Hospital,Mysore. Tel No: 9844778712 \\ E-mail: drchetak@rediffmail.com}

How to cite

Chetak KB, Gowri PS, MD Ravi. Effectiveness of Antipyretic with Tepid Sponging Versus Antipyretic Alone in Febrile Children: A Randomized Controlled Trial. J Nepal Paediatr Soc 2017;37(2):129-133.

doi: http://dx.doi.org/10.3126/jnps.v37i2.16879

This work is licensed under a Creative Commons Attribution 3.0 License. 
headaches and myalgia during the phase of rising fever, causing reduced activity to the children and thus cause anxiety to their parents. Research has established that fever is an adaptive physiologic mechanism with beneficial effects. It is a protective mechanism, except for rare circumstances of a central nervous system condition such as hypothalamic disease, the body will not allow lethal hyperpyrexia so long as hydration remains adequate and the body is provided an environment which allows for heat loss ${ }^{4}$.Most paediatricians agree that treatment of a febrile child with antipyretics is mostly for the relief of the symptoms of fever. Antipyretics are the main form of treatment to inhibit the synthesis of prostaglandins, thereby causing less stimulation of temperature set point in the hypothalamus ${ }^{5}$ by also being analgesics, lead to an improvement in the children's level of activity and alertness. This is perhaps the main reason why antipyretics have maintained their popularity among parents and have continued in use for over a century ${ }^{3,6,7}$.

Other methods for antipyresis include maintenance of adequate hydration, external cooling methods including cool baths, tepid sponging, use of fans, reducing the amount of clothing, reduction of room temperature ${ }^{1,6,7,8}$. Unlike antipyretics, external cooling acts not by reducing the elevated set point but by overwhelming the metabolically expensive effector mechanisms that have been evoked by the elevated set point ${ }^{9}$. Physical methods are widely used in treating febrile children, tepid sponging being commonly practiced in hospitals along with antipyretics, but only few small trials have evaluated the results. This study is therefore conducted to identify whether or not, the practice of tepid sponging needs to be continued.

The objectives of this study were to compare the effectiveness of tepid sponging and antipyretic drug versus only antipyretic drug in febrile children.

\section{Material and Methods}

After obtaining institutional ethical clearance, this randomized controlled trial was conducted among 500 children under the age group of 6 months to 12 years, admitted in JSS Hospital with axillary temperature $>99^{\circ} \mathrm{F}$. This study was done over two years from September 2012 to August 2014. Children who were alert, comfortable, with no active seizures, those who had not received paracetamol sixhours prior and those who were not on any antibiotics were included in the study. A written informed consent was taken from the parents. A minimum sample of 240 in each group was estimated to detect a difference of $0.2^{\circ} \mathrm{F}$ at $5 \%$ level of significance and $80 \%$ power. Randomization of children was done using computerized randomized table into two groups (control group - receiving only paracetamol and the study group - received paracetamol and tepid sponging). Digital thermometer was used to record the temperature and the initial recorded temperature was considered as zero minutes. Children in the control group received only paracetamol $(15 \mathrm{mg} / \mathrm{kg})$ within 10 mins of initial temperature. Children in the combined group ( paracetamol with tepid sponging ) received paracetamol within 10 mins of initial temperature and along with tepid sponging. Axillary temperature was monitored every 15 minutes subsequently for a period of two hours. A long mackintosh was spread under the patient. After assuring privacy, the dress was removed and the child covered with top sheet. A sponge was then used to dab over the face and neck without touching the eyes and kept at the edge of the basin. A second sponge was used to dab one arm starting from the acromion process and proceeding laterally till the fingers and then medially reaching the axilla. The sponge cloth was left in the axillary pit. The same was done for the other arm. For the legs, a sponge cloth was used to dab from the groin proceeding laterally till the feet and then medially reaching the groin. The sponge cloth was kept on the fold of the groin. The abdomen and back were dabbed with the first sponge kept at the edge of the basin. The procedure was completed in 15 minutes, when the child was dabbed dry. At 15 minutes point, temperature was checked and if it continued to be $>99^{\circ} \mathrm{F}$, sponging was administered for another 15 minutes. Later temperature was checked at similar intervals. The level of discomfort of children was also assessed at the same time points in terms of three criteria; chills, goose bumps, and irritability.

Comparison of means of axillary temperature at each point time between tepid sponging with antipyretic group and only antipyretic group were done for continuous data by unpaired t-test or Mann-Whitney test and for categorical data by z-test or Fisher's exact test. A two tailed $p$-values $<0.05$ were considered as significant.

\section{Results}

Five hundred children were studied, 246 in the study group and 254 children in the only antipyretic drug group. Majority of children in the only antipyretic group were among the age group of $8-12 y r s$ while those in combined group belonged to six months to two years. A maximum number of children in both the groups had their initial temperatures between $101-103^{\circ} \mathrm{F}$. Majority of children were diagnosed as upper respiratory tract infection, dengue fever, viral fever with gastritis, simple febrile seizures (with no active seizures). 
The mean temperature differences are shown in Table 1. By the end of two hours, no significant difference in reduction of temperature was noted between both the groups (Figure 2)

Irritability was observed in 53 children in combined group and in only three of antipyretic alone group. Chills were observed in 46 children in combined group and in only one of the antipyretic group. Goosebumps were noticed only in combined group in 10 children (Table 2). Among 254 children in only antipyretic group, $96.9 \%$ had no discomfort whereas among 246 children in combined group, only $55.7 \%$ had no discomfort (Table 2 and Figure 2). Four children among only antipyretic group had vomiting, which was statistically not significant.

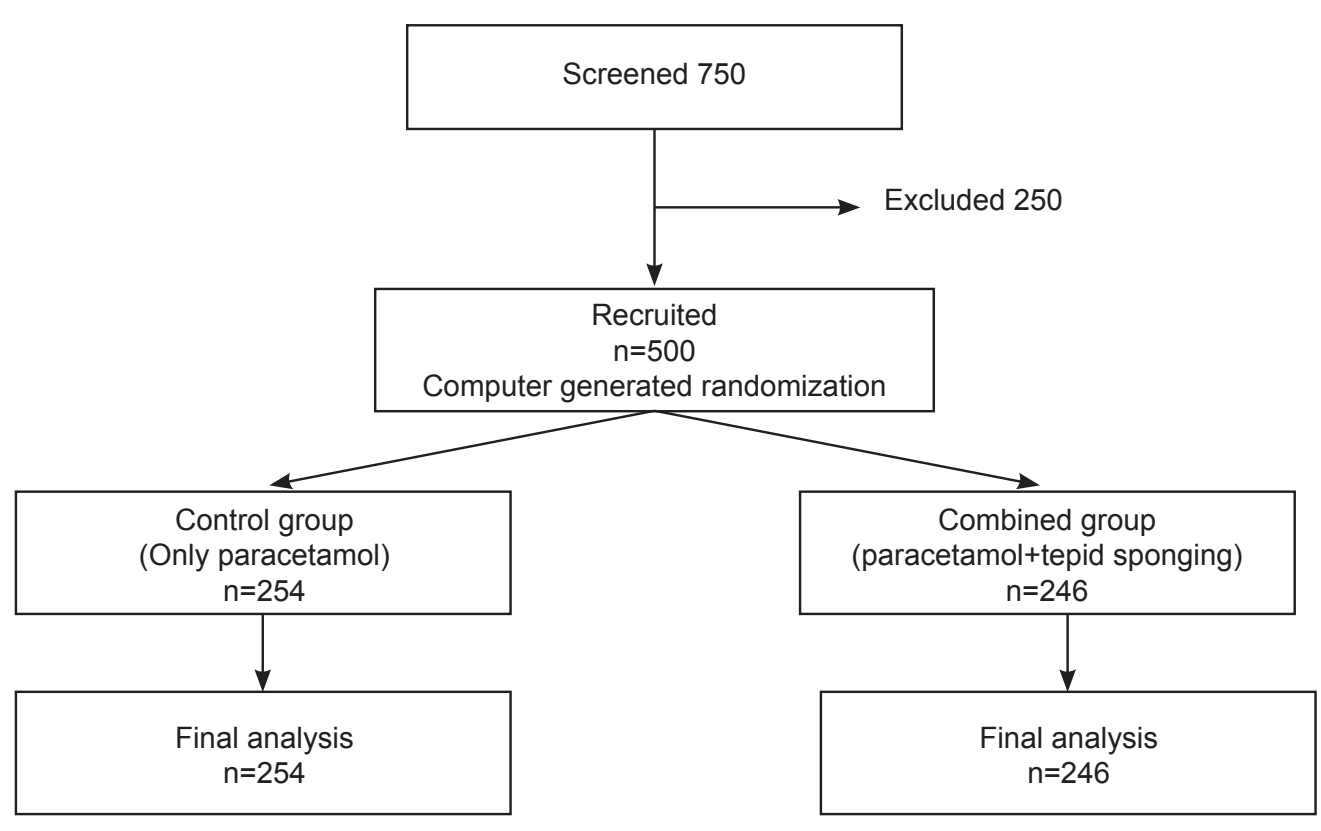

Fig 1: Randomization algorithm

Table 1: Comparison of tepid sponging and antipyretic drug versus antipyretic drug alone at each time point of temperature

\begin{tabular}{|c|c|c|c|c|c|c|}
\hline Time (minute) & $\begin{array}{l}\text { Combined group } \\
\qquad(n=246)\end{array}$ & $\begin{array}{c}\text { Control } \\
\text { group } \\
(n=254)\end{array}$ & $\begin{array}{c}\text { Mean } \\
\text { difference }\end{array}$ & $\begin{array}{c}95 \% \mathrm{Cl} \text { for the } \\
\text { mean }\end{array}$ & $t$-value & $p$-value \\
\hline Baseline & $101.63 \pm 0.99$ & $101.31 \pm 0.93$ & 0.31 & $0.14-0.48$ & 3.63 & $p=0.0004$ \\
\hline $15 \mathrm{~min}$ & $101.22 \pm 1.02$ & $101.2 \pm 0.88$ & 0.017 & $-0.15-0.18$ & 0.19 & $p=0.95$ \\
\hline $30 \mathrm{~min}$ & $100.86 \pm 0.97$ & $100.99 \pm 0.85$ & 0.13 & $-0.29-0.03$ & 1.63 & $p=0.09$ \\
\hline $45 \mathrm{~min}$ & $100.64 \pm 1.02$ & $100.74 \pm 0.83$ & 0.09 & $-0.25-0.07$ & 1.14 & $p=0.31$ \\
\hline 1hour & $100.31 \pm 1.02$ & $100.47 \pm 0.81$ & 0.16 & $-0.32-0.004$ & 1.91 & $p=0.06$ \\
\hline $1 \mathrm{hr} 15 \mathrm{~min}$ & $100 \pm 0.94$ & $100.19 \pm 0.78$ & 0.19 & $0.03-0.34$ & 2.39 & $p=0.009$ \\
\hline $1 \mathrm{hr} 30 \mathrm{~min}$ & $99.77 \pm 0.79$ & $99.9 \pm 0.76$ & 0.13 & $-0.27-0.002$ & 1.93 & $p=0.045$ \\
\hline $1 \mathrm{hr} 45 \mathrm{~min}$ & $99.59 \pm 0.66$ & $99.6 \pm 0.73$ & 0.006 & $-0.13-0.12$ & 0.097 & $p=0.55$ \\
\hline $2 \mathrm{hr}$ & $99.31 \pm 0.58$ & $99.3 \pm 0.68$ & 0.007 & $-0.1-0.12$ & 0.12 & $p=0.21$ \\
\hline
\end{tabular}

Table 2: Discomfort parameters in both the groups

\begin{tabular}{lcccc}
\hline Discomfort & $\begin{array}{c}\text { Antipyretics with tepid sponging } \\
\mathbf{n}(\%)\end{array}$ & $\begin{array}{c}\text { Antipyretics alone } \\
\mathbf{n}(\%)\end{array}$ & z-value & p-value \\
\hline Chills & $46(18.7)$ & $1(0.4)$ & 7.27 & $p<0.0001$ \\
\hline Goosebumps & $10(4.1)$ & 0 & 3.23 & $p=0.001$ \\
\hline Irritable & $53(21.5)$ & $3(1.2)$ & 7.52 & $p<0.0001$ \\
\hline No discomfort & $137(55.7)$ & $246(96.9)$ & 12.28 & $p<0.0001$ \\
\hline
\end{tabular}




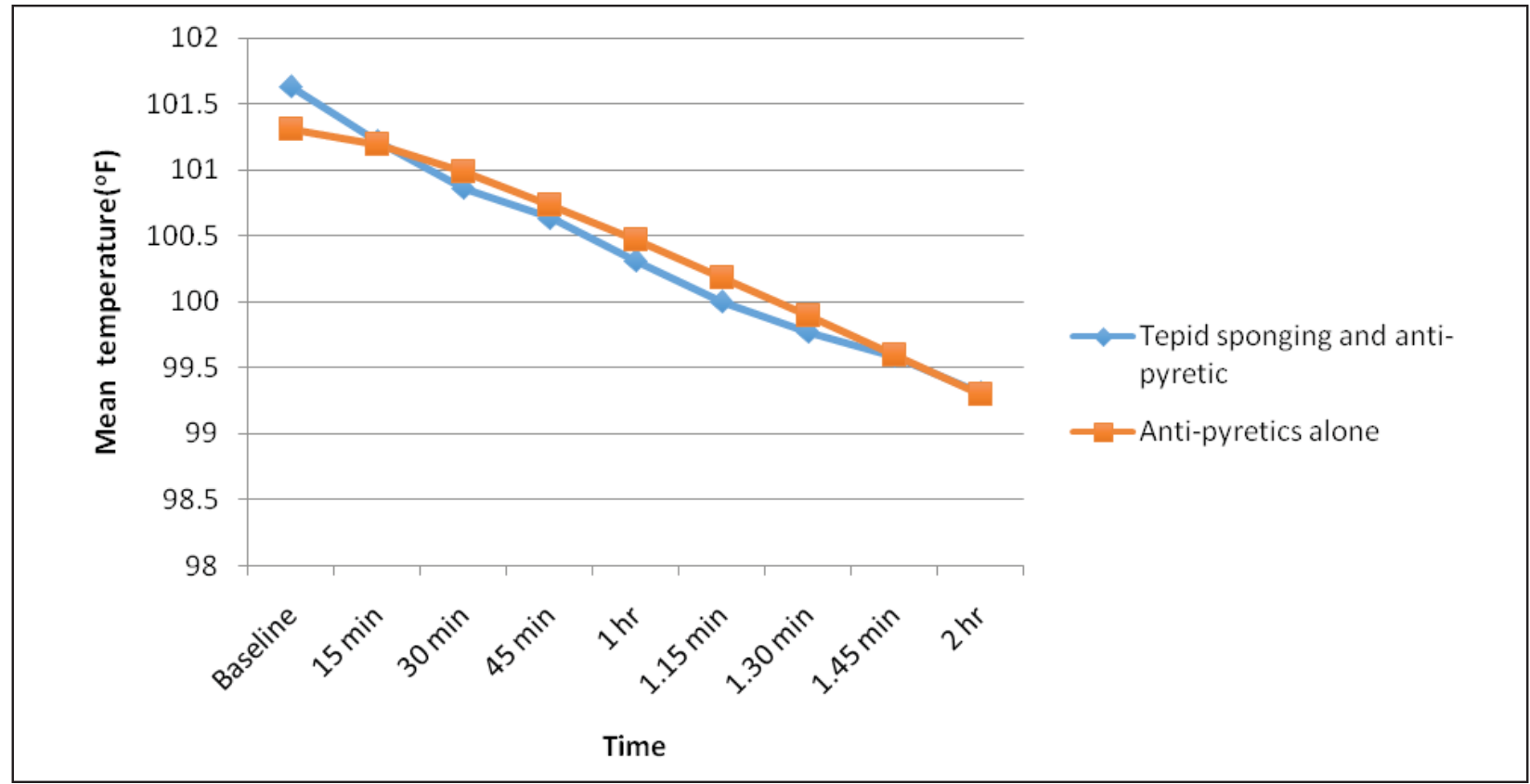

Fig 2: Changes in mean temperatures of both the groups at different time intervals.

\section{Discussion}

Fever is an increase in body temperature due to an elevated thermoregulatory set point temperature. The preoptic anterior region of the hypothalamus is the centre of the body's thermoregulatory system. It is accountable for maintaining the body at a specific set point temperature. The hypothalamus causes an increase in prostaglandin E2 (PGE2), therefore elevating the thermoregulatory set point and increasing heat conservation and production, resulting in fever.

Tepid sponging is one of the physical methods which is commonly being practiced in hospitals for reduction of temperature. Several studies have been done to compare the efficacy of these methods. Few studies have shown that addition of tepid sponging with antipyretic drug is more effective than only antipyretic drug for treatment of fever among febrile children $^{8,10,11,12,13,14,15,16}$. Studies on drug placebo and physical methods had concluded that tepid sponging has a role in reducing fever among children ${ }^{17,18}$.Axelford $P$ concluded that physical cooling methods are clearly indicated for the treatment of hyperthermia, but their use for the treatment of fever remains controversial because of their propensity to induce cutaneous vasoconstriction, shivering, sympathetic activation, and, perhaps most importantly discomfort ${ }^{19}$. Few other studies concluded that there was no difference in reduction of temperature between the two groups ${ }^{1,20,21,22,23}$.

We observed that there was no significant difference in reduction of temperature after administration of tepid sponging along with antipyretic drug as compared to antipyretic drug alone and at the end of two hours both the groups had reached the same temperature. Moreover, children in tepid sponging and antipyretic group had more discomfort rates. Similar study was conducted by Thomas et $\mathrm{al}^{20}$ in Vellore among 150 children concluded that apart from initial rapid reduction in temperature, addition of tepid sponging to antipyretic administration does not offer any advantage in ultimate reduction of temperature; moreover it may result in additional discomfort. These findings are also supported by Sharber, ${ }^{24}$ but certain other studies did not find any significant difference, although they used different criteria for assessing discomfort ${ }^{2,6}$.

\section{Conclusion}

Tepid sponging does not add to the efficacy of paracetamol in antipyresis and that addition of tepid sponging to antipyretic, results in additional discomfort for the child. This study therefore, endorses the view that antipyretic alone without tepid sponging should be the modality of therapy in children with fever. 


\section{References}

1. Feverish illness in children. Assessment and initial management in children younger than $5 \mathrm{yrs}$. London NICE; 2007.Available at https://www.nice.org.uk/ guidance/cg160/documents/feverish-illness-inchildren-update-nice-guideline2

2. Crocetti M, Moghbeli N, Serwint J. Fever phobia revisited: have parental misconceptions above fever changed in 20years? Paediatrics 2001;107(6):1241246.

3. Hay AD, Redmond NM, Costelloe C, Montgomery AA, Fletcher M, Hollinghurst S. Paracetamol plus ibuprofen for the treatment of fever in children: the PITCH randomised controlled trial. Health Technol Assess2009:13(27). DOI: 10.3310/hta13270.

4. Kluger MJ. Fever revisited. Paediatrics 1992;90(6):84650.

5. Prewitt EM. Fever: facts, fiction, physiology. Crit Care Nurse2005;Suppl:8-10,12,14 passim; quiz 18-9.

6. Casteels-Van Daele M. Management of Childhood Fever. Lancet 1991;30;338(8779):1408.K.

7. Rajeshwari. Antipyretic Therapy. IndianPediatr1997;34(5):407-13.

8. Purssell E. Physical treatment of fever. Arch Dis Child2000;82:238-239.

9. Mackowiak PA. Assaulting a physiological response. Clin Infect Dis1997;24(6):1214-216.

10. Kinmonth $A L$, Fulton $Y, \quad$ Campbell MJ. Management of feverish children at home. BMJ 1992(7);305(6862):1134-136.

11. Athirarani, M. R. Warm Sponging Versus Tepid Sponging in Febrile Children: Double Blind Randomized Controlled Trial of efficacy. IJNC2013;1:16-20. ISSN 2320-8651. Available at: http://www.i-scholar.in/index. php/ijnc/article/view/41872
12. Barton LL, Friedman AD. Efficacy of sponging vs. acetaminophen for reduction of fever. Pediatr Emerg Care 1990; 6: 255-57.

13. Mahar AF, Allen SJ, Milligan $P$, Suthumnirund $S$ et al. Tepid sponging to reduce temperature in febrile children in a tropical climate. ClinPediatr 1994;33(4):227-31

14. Barkin RM. Paediatric Emergency Medicine: Concepts and Clinical Practice. St.Louis: Mosby. 1997, $2^{\text {nd }}$ ed.

15. Bernath VF, Anderson JN, Silagy CA. Tepid sponging and paracetamol for reduction of body temperature in febrile children. Med J Aust2002;176(3):130.

16. Meremikwu MM, Oyo-Ita A. Physical methods versus drug placebo or no treatment formanaging fever in children. Cochrane Database Syst Rev 2003, (2):1-25. DOI: $10.1002 / 14651858 . C D 004264$.

17. Vivienne FB, Jeremy NA, Chris AS. Tepid sponging and paracetamol for reduction ofbody temperature in febrile children. Med J Aust2002:176; 130-31.

18. Axelrod P. External cooling in the management of fever. Clin Infect Dis 2000;315:S224-S229.

19. Thomas S, Vijaykumar C, Naik R, Moses PD, Antonisam B. Comparative effectiveness of tepid sponging and antipyretic drug versus only antipyretic drug in the management of fever among children: A randomized controlled trial. IndianPediatr 2009;46(2):133-36.

20. Newmann J. Evaluation of sponging to reduce body temperature in febrile children. Can Med Assoc $J$ 1985:132;641-43.

21. Hunter J: Study of antipyretic therapy in current use. Arch Dis Child 1973:48(4):313-15.

22. Alves JG, Almeida ND, Almeida CD.Tepid sponging plus dipyrone versus dipyrone 11alonefor reducing body temperature in febrile children. Sao Paulo Med J 2008;126(2):107-110.

23. Sharber J. The efficacy of tepid sponge bathing to reduce fever in young children. Am J Emerg Med 1997;15:188-92. 